Geopolítica(s) Revista de estudios sobre espacio y poder ISSN: 2172-3958

\title{
La extracción minera y sus implicaciones en la economía latino- americana
}

Bruno Fornillo (coord.) (2015) Geopolítica del litio. Industria, ciencia y energía en Argentina. Buenos Aires: Editorial El colectivo / CLACSO, $1^{\mathrm{a}}$ ed. 212 pp. ISBN 978-987-1497-75-1.

Las personas, comunidades, pueblos y nacionalidades tendrán derecho a beneficiarse del ambiente y de las riquezas naturales que les permitan el buen vivir. Los servicios ambientales no serán susceptibles de apropiación; su producción, prestación, uso y aprovechamiento serán regulados por el Estado

Art. 74, Constitución del Ecuador

La concepción clásica del desarrollo consideraba que la tenencia de recursos naturales era imprescindible para mejorar las condiciones de vida a través del crecimiento económico. Como señalaba Karl Marx ${ }^{1}$, la acumulación originaria de recursos, junto al control de los medios de producción, fue el origen del sistema capitalista y del actual mercado global. América Latina es una zona rica en diversos recursos, desde grandes masas de agua dulce a minerales variados; sin embargo, que una región como ésta posea grandes reservas de recursos naturales no la convierte directamente en la propietaria de los mismos. Como señala Wallerstein ${ }^{2}$, el sistema mundo divide al planeta en regiones según su aportación a la economía global: centro, periferia y semiperiferia. En este caso en concreto se destacan los países proveedores de bienes naturales, semiperiferia, y los países centrales que se desarrollan productivamente, entre otros aspectos, a costa de dichos bienes. Es por ello que el control de los recursos naturales no depende de la zona en la que se encuentren, si no de quién tenga los medios y oportunidades para explotarlos. Actualmente han surgido reclamos de explotación por parte de los países proveedores, disputándoles el control a los países centrales.

Esta compilación de investigaciones se centra en el litio, mineral que ha cobrado relevancia en las últimas décadas por su uso en las baterías Ion-litio que llevan incorporadas los nuevos instrumentos tecnológicos, desde los teléfonos móviles a

1 Karl Marx: El Capital. Libro primero, Vol. 1. El proceso de circulación del Capital. Madrid: Siglo XXI Editores, 1998.

2 Immanuel Wallerstein: El moderno sistema mundial. La agricultura capitalista y los orígenes de la economíamundo europea en el siglo XVI. Madrid: Siglo XXI Editores, 1979. 
los coches eléctricos. Ello, sumado a su asociación a las energías renovables, ha supuesto que el litio sea considerado un mineral fundamental para el desarrollo actual.

Ante la posibilidad de emerger una disputa por el control de este recurso natural en el Sur de América Latina a causa de sus reservas de litio, este libro presenta la situación de la explotación y posterior utilización del mineral en el contexto argentino. El Grupo de Estudios en Geopolítica y Bienes Naturales del Instituto de Estudios de América Latina y el Caribe de la Universidad de Buenos Aires (IEALCUBA) plasma en este libro las investigaciones realizadas a nivel individual por sus miembros. La temática central del libro, el litio, es consecuencia de las investigaciones para las tesis doctorales de los autores, quienes consideran que las características que presenta el mineral y la necesaria "«transición» hacia un sistema energético renovado, que tarde o temprano habrá que encarar a causa del agotamiento de la energía fósil y las consecuencias climáticas que produce el calentamiento global" (p. 11) revelan la importancia del mineral como alternativa para un "buen desarrollo". Por lo tanto, la identificación de este mineral como una riqueza afecta directamente a los tres países latinoamericanos que poseen "el 80 por ciento de las reservas probadas del elemento químico” (p. 11), Bolivia, Chile y Argentina.

Las publicaciones anteriores a este libro se han centrado en las posibles problemáticas que la explotación del mineral acarrearía, pero, a juicio los autores, se centrarían demasiado en Bolivia y Chile, por lo que han buscado posicionar a Argentina dentro del mapa regional del litio.

El libro presenta la situación de la explotación del litio en el norte de Argentina, describiendo aspectos como las redes de comercio internacional que podrían tejerse, el desarrollo productivo y científico y los conflictos territoriales internos que supone su extracción. Buscando mostrar a los diferentes actores implicados y su vinculación con el mineral, abordan el tema de forma genérica, destacando su relevancia en el comercio internacional, para terminar centrándose en la zona noroeste argentina, donde se sitúan las reservas de litio nacionales.

Tras una introducción sobre las zonas donde se encuentra presente el mineral y los usos que actualmente tiene, el libro se organiza en cuatro capítulos y un epílogo, que parten de una hipótesis común: "para comprender cómo y por qué entran en conflicto diferentes grupos y actores, no podemos dejar de lado cómo se entrelazan las distintas estructuras de las cuales forman parte, así como los distintos escenarios que enfrentan en cada caso" (p. 19). En esta situación conflictiva los textos destacan tres grandes actores que presentan diferentes concepciones sobre la explotación del litio en tierras pobladas por comunidades indígenas.

El primero de ellos son las empresas de explotación de litio que se han instalado en los salares y que poseen la tecnología necesaria para el cometido. Estas empresas representan el paso entre lo local y lo global, tejiendo relaciones con las comunidades que habitan los salares, con los gobiernos provinciales, con el nacional y con los socios internacionales para controlar el mercado global. Este actor pretende llevar a cabo la extracción del mineral con mano de obra local, a través de los permisos que le concede el gobierno provincial o nacional, para exportar el recurso a los países dominantes. Este modelo de explotación perpetúa la extracción de riquezas de unos países para el desarrollo tecnológico de los centrales. 
Frente a ellas, las comunidades indígenas apelan a su vinculación con el territorio aportando alternativas a este modelo extractivo. Estas poblaciones se basan en la idea del "buen vivir", es decir, en la concepción de que el ser humano es parte del entorno natural y social que le rodea; el modelo del buen vivir busca el equilibrio con la naturaleza, utilizando de ella lo necesario para la supervivencia. Esta perspectiva entra en conflicto con la de las empresas, se reactiva su identidad indígena y, con ello, su reclamo de soberanía del territorio bajo este modelo, anteponiéndose a demandas ambientales. Por lo tanto, quieren intervenir políticamente en la explotación del mineral en sus territorios.

El tercer actor que señalan estas investigaciones son los gobiernos provinciales y el nacional, quienes ven la posibilidad de una inversión extranjera en el sector minero, cuyas consecuencias económicas son beneficiosas. En este caso, la pretensión del gobierno nacional argentino va más allá de la inversión extranjera y busca desarrollar una industria de baterías de ion-litio, lo que permitiría que el recurso no se destinara a los países centrales y colocaría a Argentina como exportador de tecnología y no exclusivamente de materia prima.

Estos tres actores se encuentran presentes a lo largo del libro, a pesar de que cada capítulo trata aspectos diferentes del conflicto central. El primero de ellos (pp. 19-56), escrito por Julián Zícari, se centra en las actuales estrategias de extracción minera en Sudamérica y su posibilidad de modificar el intercambio tradicional de materias primas de los países periféricos hacia las zonas desarrolladas. Para ello hace un recorrido sobre este fenómeno desde los años noventa, destacando la importancia que ha adquirido el litio a nivel internacional al ser considerado una energía renovable que puede sustituir a la energía fósil en el panorama tecnológico.

Su teorización sobre un modelo de intercambio global que posicione a Sudamérica en un nuevo lugar considera tres premisas. La primera de ellas, que el mineral se encuentra en diversas parte del mundo, lo que limita el monopolio extractivo. La segunda, que la demanda actual de litio para la fabricación de baterías puede diluirse en un contexto tecnológico que se modifica a gran velocidad por el desarrollo en este campo, lo que se vincula directamente con la última premisa, que existe una variedad de minerales que podrían sustituirlo.

En el segundo capítulo (pp. 57-90), Bruno Fornillo expone la teoría de que poseer reservas de litio no posiciona a Argentina como un país que pueda obtener grandes beneficios si no hace un buen uso de las mismas. Refleja la necesidad de invertir en la fabricación de baterías de litio para su exportación dentro de un mercado tecnológico creciente como es el automotriz. Por lo tanto, no aboga por una revalorización del material, sino por una inversión en innovación.

Ariel Slipak se centra en el tercer capítulo (pp. 91-122) en que la extracción de litio no sólo conlleva un impacto ambiental y supone una oportunidad de desarrollo para el país, si no que presenta consecuencias directas en el mercado laboral y en la redistribución de beneficios, las cuales analizada.

En el último capítulo (pp. 123-166), Andrea Florencia Puente y Melisa Argento presentan su trabajo de campo con las poblaciones indígenas de los salares, destacando su demanda de soberanía territorial.

Con la intención de ampliar la información, en el anexo incluyen una breve explicación sobre el montaje de las baterías de litio; un cuadro donde se desglosa cada proyecto de extracción, con la empresa responsable y la localización del salar; 
dos mapas generales sobre la ubicación de los salares y las comunidades que los habitan; una descripción de los métodos de extracción de litio; y unos breves apuntes sobre el trabajo de campo que las autoras realizaron para acceder al discurso de las comunidades indígenas.

Lo que este libro viene a presentar son dos lógicas de desarrollo distintas. Por un lado, aquella que condena a Argentina a ser exportador de materias primas, limitando su participación política y económica, generando conflictos territoriales internos y manteniendo su rol de proveedora para el desarrollo de las zonas centrales, facilitándoles la transición energética. Por el otro lado, la lógica de una explotación minera acorde a las necesidades, con implicación de las comunidades indígenas y la producción de baterías de litio en Argentina, situación que posicionaría ventajosamente al país en el mercado global.

La propuesta de los autores es optar por la segunda lógica, recomendando una coalición regional que incluya, no sólo a los poseedores de reservas de litio, sino a aquellos países con capacidad para producir baterías de litio e invertir en investigación, como Brasil; de este modo apuestan por una autonomía sudamericana. Sin embargo, se encuentran ante la necesidad de incluir las demandas indígenas y considerar su concepción del buen vivir dentro del modelo extractivo planteado. A su vez, se enfrentan a un acontecimiento que lleva presente en los salares desde los años noventa, donde la intensificación de la extracción y el conflicto son consecuencia de la relevancia global que ha adquirido el mineral. Por lo tanto, estos textos se inscriben dentro del debate sobre el postdesarrollo, optando por el fortalecimiento de las relaciones comerciales latinoamericanas.

Eva Fernández Arrúe Universidad Complutense de Madrid Email: efarrue@hotmail.com 